\title{
La minería en Ecuador. Pasado, presente y futuro
}

\author{
Rocío Estupiñan, Paola Romero, Mishel García, Daniel Garcés y Priscila Valverde \\ Escuela Superior Politécnica del Litoral, ESPOL, Facultad de Ingeniería en Ciencias de laTierra, Campus Gustavo Galindo \\ Km 30.5 Vía Perimetral, P.O. Box 09-01-5863, Guayaquil, Ecuador. \\ testupin@espol.edu.ec; plromero@espol.edu.ec; mistagar@espol.edu.ec; ogarces@espol.edu.ec; priesval@espol.edu.ec
}

\begin{abstract}
RESUMEN
El Gobierno Nacional del Ecuador busca consolidar al sector minero como el segundo sector exportador, enfocando las acciones en garantizar las inversiones y combatir nuevamente la minería ilegal. Es así que el gobierno presentó oficialmente la nueva Política Minera del Ecuador 2019 - 2030, y se encuentran en discusión nuevas reformas a la Ley Minera para incentivar la inversión nacional y extranjera. Además, se está desarrollando un mayor control en los sectores mineros por parte del Ministerio del Interior para combatir la minería ilegal, que genera un alto riesgo de seguridad para los trabajadores de las operaciones mineras y para las poblaciones cercanas, debido a los enfrentamientos armados y al lavado de dinero. El objetivo del trabajo es diagnosticar el estado actual de la minería en Ecuador, en diferentes contextos: legal, ambiental, social y económico. Se espera un crecimiento del Producto Interno Bruto (PIB) del $4 \%$ en la minería metálica para el año 2021. Los tres minerales no metálicos más explotados son: piedra caliza, arcillas y piedra pómez. Y el mayor volumen de explotación se da en los materiales de construcción, que se distribuyen por todo el país. Los conflictos sociales son un tema fundamental en el sector minero, donde existen diferentes posturas sobre aquellos aspectos como el desarrollo económico, la conducta empresarial, la gestión del ciclo de vida, el bienestar de la comunidad, las condiciones de trabajo y la responsabilidad medioambiental.
\end{abstract}

Palabras claves: minería artesanal, gran minería, reforma ley minera, riesgo ambiental.

\section{Mining in Ecuador. Past, present and future}

\begin{abstract}
The Ecuador National Government aims to consolidate the mining sector as the second export sector, focusing the actions on guaranteeing the investments and fighting again illegal mining. Therefore, the government officially presented the new Ecuador Mining Policy 2019 - 2030, and new reforms to the Mining Law are under discussion to encourage domestic and foreign investment. In addition, more control in the mining sectors by the Ministry of the Interior is being developed to combat illegal mining, which generates a high security risk for mining operation workers and for nearby populations, due to armed clashes and money-laundering. For this study the objective has been to diagnose the current state of mining in Ecuador, in different contexts: legal, environmental, social and economic. A 4\% GDP contribution to growth in metallic mining is expected by the year 2021. The three most exploited non-metallic minerals are: limestone, clay and pumice. In addition, the largest exploitation volume occurs in construction materials, which are distributed throughout the country. Social conflicts are a fundamental issue in the mining sector, where there are different points of view about those different aspects such as economic development, business conduct, life cycle management, community welfare, working conditions, and environmental responsibility.
\end{abstract}

Keywords: artisanal mining; environmental risk; large-scale mining; mining policy reform 


\section{Introducción}

La minería en el Ecuador inicia aproximadamente 3500 A.C con la cultura Valdivia considerada como la primera civilización alfarera de América, donde realizaba la extracción de la arcilla para la fabricación de las cerámicas. Otras culturas como la Machalilla y Chorrera tuvieron gran importancia en el desarrollo de la cerámica en el Ecuador.

La culturaTolita se destaca por sus trabajos con metales, técnicas de extracción, aleaciones, uso del oro, cobre, plata y platino. La cultura precolombina para obtener los metales realizaba el bateo de oro en los ríos o la explotación superficial mediante socavones o galerías. Durante el Imperio del Tahuantinsuyo se aprovecharon principalmente los siguientes recursos minerales: oro, plata, cobre, piedras preciosas y obsidiana.

En la época colonial existieron importantes ciudades fundadas por la importancia aurífera: de Sevilla de Oro, Logroño, Valladolid y Loyola. En el siglo XVI existe el desarrollo de la metalurgia precolombina $y$ el auge minero, donde las zonas de mayor productividad fueron Zaruma y Portovelo y su auge minero duró hasta el siglo XVII y se convirtió en una actividad marginal hasta inicios del siglo $X X$ que repunta nuevamente (Gutierrez, A, 2002).

Se inicia un nuevo auge minero a partir de los años 1980 por el incremento del precio del oro. Los mineros artesanales descubren importantes yacimientos auríferos del país Nambija, Guayzimi, Chinapintza, Ponce Enríquez. Las actividades se concentraban en una minería artesanal que realizaba la recuperación de oro con amalgamación y que presentaba carencia de planificación y tecnología.

Aproximadamente en los primeros años del Siglo $X X$ se inició la pequeña minería en el Ecuador. En 1896 hasta 1950 se adjudica a South American Development Company SADCO el área minera de Portovelo-Zaruma. Después del retiro de SADCO, se crea la empresa estatal CIMA formada por Municipio de Zaruma y extrabajadores de SADCO y quiebra en 1978. En los años 1990 se construyen las primeras plantas tecnificadas para recuperación de oro de pequeña escala usando: cianuración, carbón activado y procesos de electrólisis (Espí, J.A. 2001).

Esta publicación realiza un diagnóstico de los cambios en que ha tenido el Marco Legal de la actividad Minera en el Ecuador en los últimos años, en base a la Nueva Política Minera, analizando aspectos técnicos, económicos, ambientales y sociales. Además, se incluye el estado actual de la actividad minera, los Derechos mineros, diferenciados entre minería artesanal, pequeña, mediana y gran minería, libres aprovechamientos de materiales de construcción para la obra pública, plantas de beneficio y licencias de comercialización.

Los resultados obtenidos del informe Responsible Mining Index realizado en el 2018 por la fundación
Responsible Mining Foundation, con datos del año 2017 correspondientes a 30 empresas mineras a gran escala con sede en 16 países. La metodología empleada por Responsible Mining Foundation mide la aplicación de prácticas y políticas aplicadas por parte de las empresas mineras en aspectos económicos, ambientales, sociales y de gobernanza. Analizando seis áreas temáticas relacionadas con la minería responsable:

- Desarrollo económico: donde solo tres empresas Anglo America, Vale, Newmont Mining, muestran el más alto desempeño global superior a las demás áreas temáticas.

- Conducta empresarial: los niveles de desempeño son relativamente homogéneos y muestra la mayor puntuación media en comparación con el resto de las áreas temáticas.

- Gestión del ciclo de vida: las 30 empresas analizadas muestran un desempeño muy variado.

- Bienestar comunitario: los niveles de desempeño en el ámbito del Bienestar Comunitario son bajos, presentan un rendimiento poco satisfactorio en relación con otras áreas temáticas.

- La información suministrada de las 30 empresas mineras sobre la relación existente con la minería artesanal y a pequeña escala, muestra que solo 6 de estas desarrollan estrategias de colaboración y 8 indican que eso no les concierne.

- Condiciones de trabajo: las Condiciones deTrabajo son el área temática con más bajo desempeño global, los niveles de desempeño en este ámbito se distribuyen con relativa homogeneidad entre las 30 empresas.

- Responsabilidad Medioambiental: el desempeño de las empresas en este ámbito muestra una progresión gradual.

El conocimiento sobre las principales debilidades de la minería a gran escala a nivel mundial constituye una información fundamental para el análisis de la situación actual del Ecuador, la que tiene perspectivas de producción a gran escala a partir de diciembre del 2019, por lo cual conocer sobre estas buenas prácticas y políticas constituyen lineamientos de aplicación hacia la minería responsable.

De los cinco proyectos estratégicos de minería metálica en Ecuador se observa que solo dos empresas presentan información pública y detallada en su página web sobre las seis áreas temáticas evaluadas en el informe Responsible Mining Index.

Actualmente el Ecuador se encuentra en una etapa de exploración minera de metálicos, y constituye una de las prioridades de desarrollo económico del Gobierno, por lo cual la exploración de estos recursos constituye una valiosa y justificada inversión. Las tendencias del aumento de la producción de minerales metálicos es probable que sean directamente proporcionales al incremento de la población mundial y niveles de vida. "Es probable que los elementos con precios altos en relación con su abundancia, merca- 
dos grandes y producción limitada $(<19 \%$ del total global) de China sean los más atractivos. Estos incluyen oro, elementos del grupo del platino, uranio, litio, cobalto, niobio, níquel, cromo, titanio, potasio y hierro" (Price, 2019).

La posible escasez de la mayoría de los metales van a requerir a futuro avances significativos en exploración, explotación, y procesamiento de minerales, es por esto "la necesidad de salvaguardar el acceso a depósitos conocidos y metas prometedoras debe considerarse como una prioridad de primer orden y las decisiones políticas sobre este tema deben ser asistidas por conjuntos de criterios objetivos, incorporando la planificación de la exploración y la minería a las políticas de uso de la tierra a varias escalas y herramientas de gestión territorial" (Mateus and Martins, 2019).

Los conflictos sociales constituyen una posible limitante del desarrollo de un proyecto minero, por lo cual su análisis es fundamental para garantizar el éxito del proyecto, sin embargo en muchas ocasiones su análisis es considerado un tema subjetivo, motivo por el cual el desarrollo de metodologías para evaluar las percepciones subjetivas con base a un análisis de múltiples posiciones de los actores involucrados en el sector minero del Ecuador constituye un tema de gran relevancia para la resolución de conflictos sociales y para conocer la percepción sobre las políticas actuales en el sector minero. "Los resultados resaltan cuatro discursos distintos: (1) extractivismo responsable; (2) autodeterminación local; (3) desarrollo económico nacional; y (4) desarrollo económico local. Los análisis discursivos sugieren que las posiciones mineras se construyen para disputar el poder en: toma de decisiones, la promulgación de valores y derechos, y la distribución desigual de los beneficios económicos y las cargas socio-ambientales asociadas con la minería" (Vela-Almeida et al., 2018).

El nivel de aceptabilidad de los proyectos mineros se ha demostrado que depende de las dinámicas territoriales en el sector, esto se muestra en dos casos de minería en Intag ubicado en Imbabura y Mirador ubicado en Zamora Chinchipe. “De hecho, en el caso de Intag, un grupo heterogéneo de personas logró construir una identidad territorial y un proyecto político que imaginó al valle como un lugar para el desarrollo alternativo. Este no ha sido el caso en Mirador, a pesar de la presencia de un grupo indígena que habita el territorio que dicen ser su hogar ancestral. Más allá de la identificación étnica como indígena, los reclamos políticos de los Shuar sobre el territorio que rodea al Mirador no siempre son consistentes y / o compartidos por las diversas comunidades, asociaciones y federaciones. Estas diferencias entre Intag y Mirador están claramente relacionadas con los procesos históricos divergentes de la producción del territorio en cada caso" (Avci and Fernández-Salvador, 2016).
El debate referente a la formalización / regulación de la minería artesanal y a pequeña escala, destaca la necesidad de capacitar a los mineros locales en conjunto con una nueva legislación, en el caso de Portovelo-Zaruma esta estrategia está destinada a tener un impacto limitado en el sector. "Y se sugiere que la capacitación y el desarrollo de capacidades deben llevarse a cabo junto con un debate público amplio e inclusivo sobre las problemáticas asimetrías de poder en las operaciones mineras y que conducen a una distribución injusta de la riqueza, los riesgos y la contaminación. Más concretamente, los procesos y la participación de abajo hacia arriba, que involucran a la sociedad civil" (Fraekaland, 2018).

\section{Metodología}

Este traabjo fue desarrollada mediante la revisión, análisis y contraste de la siguiente información:

- Revisión y contraste de artículos de los principales medios de prensa escrita.

- Reportes del Banco Central.

- Legislación vigente en el ámbito geológico, minero, ambiental, seguridad y salud ocupacional.

- Base de datos de las concesiones mineras solicitada a la ARCOM.

- Revisión de páginas web y redes sociales de los principales proyectos mineros a gran escala de recursos metálicos.

- Revisión de Blogs y páginas webs de grupos ambientalistas.

- Entrevistas a profesionales del sector minero, consultor ambiental, universidad, y a la Agencia de Regulación y Control Minero (ARCOM).

- Encuestas realizadas al sector de minería artesanal y pequeña minería en dos de las principales zonas mineras de recursos metálicos del país: Zaruma, Portovelo, Santa Rosa (estudio realizado en el año 2011 con el Ministerio de Recursos Naturales No Renovables) y Ponce Enríquez (estudio realizado en el año 2016 y 2018 como parte del programa Vínculos con la Sociedad de la ESPOL).

- Encuestas realizadas al sector de minería artesanal y pequeña minería para recursos no metálicos en el área de estudio de Santa Elena (estudio realizado en el año 2017 como parte del programa Vínculos con la Sociedad de la ESPOL).

En base al contraste y validación de esta información bibliográfica, entrevistas y encuestas realizadas en el sector de recursos metálicos y no metálicos, se procedió a realizar la descripción de la situación de la minería en el Ecuador en el contexto legal, técnico, social, ambiental y económico, para finalizar con un diagnóstico de su perspectiva actual y futura. 


\section{Resultados}

\section{Marco legal}

En 1830 se dictó la primera ley para promover el fomento de las minas, posteriormente en 1900 se estableció el plazo para el arrendamiento de minas. En 1937 se crea la Ley de Minería que determinó que los minerales que están en el subsuelo son de dominio del estado. En 1991 se dictó una nueva Ley de Minería que incorpora y define los derechos mineros que proviene de las concesiones mineras de exploración (duración 2 años) y explotación (duración 20 años).

En 1997 se aprobó el Reglamento Ambiental para Actividades Mineras, con la finalidad de ser un instrumento normativo para la regularización ambiental nacional del sector minero (Carrión, A, 2017).

En el 2009 se expide una nueva Ley de Minería con el objetivo de promover como un sector estratégico a la minería para que sea atractivo para la inversión de grandes empresas mineras, donde se requería administrar, regular, controlar y gestionar a este sector. Además, se define una estructura institucional del sector minero e incluye al cierre de minas entre las ocho fases de la actividad minera.

En el 2013 existieron reformas a la Ley de Minería orientadas a reducir el número de permisos requeridos para ejecución de la actividad. Además, existieron reformas en relación con los impuestos, que consideraba ingresos extraordinarios a los percibidos en ventas a precios superiores a los pactados en los contratos, mientras en esta reforma se indica que los ingresos extraordinarios son los percibidos después que las inversiones hayan sido recuperadas.

La minería es considerada entre los trabajos peligrosos por la Organización Internacional del Trabajo, por lo cual es imprescindible garantizar las condiciones de seguridad y salud en el trabajo, dada la importancia de este tema, en el 2014 se aprueba el Reglamento de Seguridad y Salud en el trabajo en el Ámbito Minero, que tiene como objeto: establecer normas para la aplicación de la Ley de Minería, a fin de precautelar la seguridad y salud en el trabajo de las personas en todas las fases de la actividad minera como lo señala el Capítulo VII, Art.27 de la Ley de Minería. A partir de este reglamento se dispondrá de los lineamientos generales para realizar la actividad de prevención de riesgos laborales bajo los regímenes especiales de minería artesanal, pequeña, mediana y gran minería (Asamblea Nacional, 2014).

EI Mandato Constituyente Minero del Ecuador fue aprobado por la Asamblea Nacional el 18 de abril del 2008, y fue publicada el 29 de enero del 2009 en el registro oficial la nueva Ley de Minería (Asamblea Nacional, 2009). Éste mandato fue promulgado con el objetivo de regularizar las concesiones mineras de todo el país mediante la aplicación de mecanismos de regulación rigurosos. Por ejemplo, las concesiones mineras fueron extinguidas en los siguientes ca- sos: (i) por incumplimiento de la legislación minera en aspectos como la no presentación de estudios de impacto ambiental, (ii) escasa evidencia de la realización de un proceso de consulta para la elaboración del estudio de impacto ambiental, (iii) cuando las actividades de explotación se desarrollaban dentro de áreas naturales, bosques, áreas protegidas, zonas de amortiguamiento, y (iv) cuando las actividades mineras afectaban las fuentes de agua. Estos mecanismos de regulación también permitieron fortalecer la interculturalidad del país mediante la protección de los derechos de los pueblos y nacionales, principalmente indígenas y afro-descendientes.

Otro de los aspectos fundamentales establecidos en la Ley de Minería, fue la posibilidad de renovar el tiempo de concesión después de terminado el respectivo período de actividades. Es decir, los concesionarios mineros que renueven sus permisos de funcionamiento gozarían de 25 años adicionales para llevar a cabo sus actividades. De cara a esta reforma, el país diferenció a los concesionarios mineros registrados antes y después del año 2005. Por ejemplo, a los concesionarios mineros registrados después este año, se les otorgó los años establecidos en esta ley; mientras que, el plazo de concesión para los inscritos antes del año 2005 fue menor a 25 años. Este Mandato Constituyente Minero tuvo como objetivo no sólo fortalecer el descubrimiento de nuevos yacimientos y la prolongación del tiempo efectivo de explotación en las concesiones existentes sino también la captación de nuevos y grandes capitales de inversión mediante la realización de proyectos con una mayor oportunidad de generación de regalías.

Además, esta ley contempló la limitación de los títulos mineros ya sean individuales o colectivos a no exceder más de 150 ha de concesión para personas naturales o jurídicas. Similarmente, se cancelaron concesiones mineras que pertenecían a trabajadores del sector público, con el fin de minimizar el manejo de información sensible y "privilegiada" por ocupación de cargos públicos y que es de interés de organizaciones gubernamentales como el Ministerio de Energía y Recursos Naturales no Renovables, Ministerio del Ambiente y Ministerio de Minería.

Con el fin de continuar con el proceso de normalización del proceso de regularización de las concesionarias, en noviembre del 2009 se aprobó el Reglamento General de la Ley de Minería (Ministerio de Recursos Naturales no Renovables, 2009). Ésta ley estableció la creación de nuevos formularios de procesos para solicitar nuevas concesiones. Sin embargo, el proceso de elaboración y formulación de estos formularios se prolongó hasta el año 2016, tiempo en el cual no se registraron nuevas concesiones de tipo de pequeña y de gran minería. Esto ocasionó una pobre activación de la minería contrario a las aspiraciones del gobierno ecuatoriano. A pesar de que la pequeña minería y gran minería no experimentaron el crecimiento esperado, la minería artesanal y de libre aprovechamiento 
(en su mayoría de cascajo, el cual es material base con fines de utilización y no de generación de regalías) reportó la obtención de concesiones hasta el cierre del catastro minero en el año 2018.

La Agencia de Regulación y Control Minero (ARCOM), fue creada mediante en el Gobierno de Rafael Correa, en la Ley No. 045, publicada en Registro Oficial No. 517 de 29 de enero de 2009; con la finalidad de controlar y regular las actividades en el sector minero del Ecuador. Sin embargo, su función y alcance está limitado por el escaso personal técnico con el que cuenta ARCOM.

Las primeras acciones de ARCOM estuvieron encaminadas a la regularización de la minería informal y a incentivar que el sector de minería artesanal se transforme a pequeña minería mediante la asociatividad, con la finalidad de mejorar sus condiciones laborales y de seguridad mediante la introducción de la mecanización en la minería artesanal. Además, los primeros años de inició del ARCOM se promulgó la importancia de lo que el cierre de minas dentro de las etapas de los proyectos mineros. Actualmente por la política minera actual ARCOM está orientada al control de la minería ilegal, que ha sido un problema que se ha manifestado con mayor intensidad en el 2018 y 2019.

Históricamente, las regulaciones mineras han cambiado con el tiempo y en función de las necesidades nacionales de ese entonces (ver Fig. 1). Desde el 2009 hasta la actualidad, la Asamblea Nacional ha trabajado en la reforma de Ley de Minería. El Plan Nacional de Desarrollo Minero (Ministerio de Minería, 2016) fue actualizado el 4 de junio del 2019, donde el gobierno nacional presentó oficialmente la nueva política minera del Ecuador 2019 - 2030 (World Energy Trade, 2019). Ésta nueva política minera que se basa en 6 ejes fundamentales: 1) normativa, 2) gestión administrativa, 3) regulación y control de la minería ilegal, 4) desarrollo económico, 5) investigación y desarrollo, y 6) sostenibilidad ambiental y social.

En el ámbito de la reforma normativa y de gestión administrativa en la Ley de Minería, el gobierno ecuatoriano ha sumado esfuerzos para regularizar las actividades de minería artesanal, beneficiando a 414 labores mineras en diversas provincias del país en el año 2017. El objetivo de esta reforma es el de viabilizar el desarrollo de la industria minera cumpliendo con las exigencias del sector y generando seguridad jurídica. Esto ha implicado la corrección de vacíos legales, minimizando interpretaciones subjetivas de la ley. Además, la mejora en la eficiencia de la gestión administrativa ha permitido como parte de esta reforma, optimizar el tiempo de respuesta a solicitudes para otorgamiento de concesiones para las actividades de pequeña minería. Dentro de los mecanismos de optimización se encuentran: (i) igualdad de acceso mediante el manejo de medios ofimáticos, garantizando transparencia y seguimiento, (ii) reducción de requisitos y simplificación de trámites, (iii) ingreso de plan de trabajo, inversión y área de interés en medios electrónicos, y la (iv) promoción de la asociación entre mineros informales $y$ artesanales impulsando un modelo de economía popular y solidaria.

Las políticas de regulación y control de las actividades mineras de carácter ilegal han movilizado diver-

\begin{tabular}{ll}
\hline EJE & POLÍTICAS PÚBLICAS \\
\hline Desarrollo económico & $\begin{array}{l}\text { Incrementar y diversificar la producción del sector minero } \\
\text { Fomentar el aprovechamiento de los recursos minerales con } \\
\text { responsabilidad ambiental. } \\
\text { Fortalecer el vínculo comunitario y la responsabilidad social de } \\
\text { quienes realizan actividades mineras. }\end{array}$ \\
& $\begin{array}{l}\text { Promover la investigación, innovación, transferencia tecnológica, } \\
\text { y el emprendimiento para el desarrollo del sector minero }\end{array}$ \\
Investigación y desarrollo & $\begin{array}{l}\text { Promover una administración pública articulada, oportuna y } \\
\text { eficiente }\end{array}$ \\
Gestión y administración & $\begin{array}{l}\text { Mejorar la capacidad de administración, regulación y control del } \\
\text { Estado a las actividades mineras, incluyendo la prevención, } \\
\text { Regulación, control y combate a la } \\
\text { minería ilegal }\end{array}$ \\
combate y sanción de la minería ilegal \\
Promover el mejoramiento del marco normativo para viabilizar el \\
desarrollo de la industria minera, acorde con las nuevas \\
exigencias del sector y que permita la generación de seguridad \\
juridica
\end{tabular}

Tabla 1: Nueva política minera del Ecuador 2019 - 2030 (Ministerio de Energía y Recursos Naturales No Renovables, 2019). Table 1. New mining policy of Ecuador 2019 - 2030 (Ministry of Energy and Non-Renewable Natural Resources, 2019). 
sos organismos del estado como la Policía Nacional del Ecuador, la Agencia de Regulación y Control Minero (ARCOM), Fiscalía General del Estado y la Secretaría de Gestión de Riesgos con el fin de identificar, sancionar y suspender actividades ilícitas de minería. La minería ilegal es un delito tipificado en el Código Orgánico Integral Penal que fomenta otros delitos conexos como el lavado de activos, uso de armas e inseguridad. Recientemente, se suscitó un enfrentamiento armado entre mineros ilegales en la provincia de Imbabura dejando un saldo de diez personas heridas. Este tipo de violencia que provoca herida leves o mortales generalmente no es reportada, a pesar de suscitarse con frecuencia en los sectores mineros del país. Existen trabajadores cuyo principal sustento económico se basa en la actividad minera, la mismas que se realizan en las áreas urbanas influenciadas por la alteración de las condiciones físicas producto de esta actividad (zonas de exclusión). Estos trabajadores fueron reubicados fuera de las zonas de exclusión con el fin de mitigar el impacto económico y social que el cese de éstas actividades produciría.

La actual reforma a la Ley de Minería del 2019 tiene como objetivo aumentar el nivel de gestión y modernización de las técnicas y procedimientos utilizados en el sector minero a través de la investigación. Con miras a alcanzar este objetivo, el Instituto Nacional de Investigación Geológico, Minero, y Metalúrgico (INIGEMM) se encarga de desarrollar actividades de investigación geológica-minera, participar en conferencias y talleres internacionales capacitando a su personal. La Tabla 1 detalla los ejes impulsados en la nueva política minera del Ecuador 2019-2030 con sus respectivas políticas públicas.

A continuación, se presentan las principales leyes y reglamentos aplicables al sector minero (Asamblea Nacional, 2008, 2009, 2011, 2015, Agencia de Regulación y Control Minero, 2012):

- Constitución del Ecuador.

- Ley de Minería.

- Ley de Gestión Ambiental.

- Ley Orgánica de Incentivos para Asociaciones Público-Privadas y la Inversión Extranjera.

- Ley Orgánica de la Economía Popular y Solidaria y del Sector Financiero Popular y Solidario.

- Ley Orgánica del Régimen Tributario Interno.

- Reglamento General a la Ley de Minería.

- Reglamento de Contabilidad Minera.

- Reglamento Ambiental de Actividades Mineras.

- Reglamento del Régimen Especial de Pequeña Minería y Minería Artesanal.

- Reglamento del Régimen Especial para el Libre Aprovechamiento de Materiales de Construcción para la Obra Pública.

- Reglamento Especial para Explotación de Materiales Áridos y Pétreos.

- Reglamento de Seguridad y Salud en el Trabajo en el Ámbito Minero.

\section{Contexto ambiental}

En el 2008 se reconoció los derechos de la Naturaleza en la Constitución, lo que constituyó un importante hecho histórico a nivel mundial. Sin embargo, para algunos sectores esto fue considerado una utopía y fue fuertemente criticado por algunas comunidades, grupos políticos y ambientalistas indicando que no se estaba garantizando estos derechos, dado que señalan que se habían otorgado algunas concesiones en zonas protegidas.

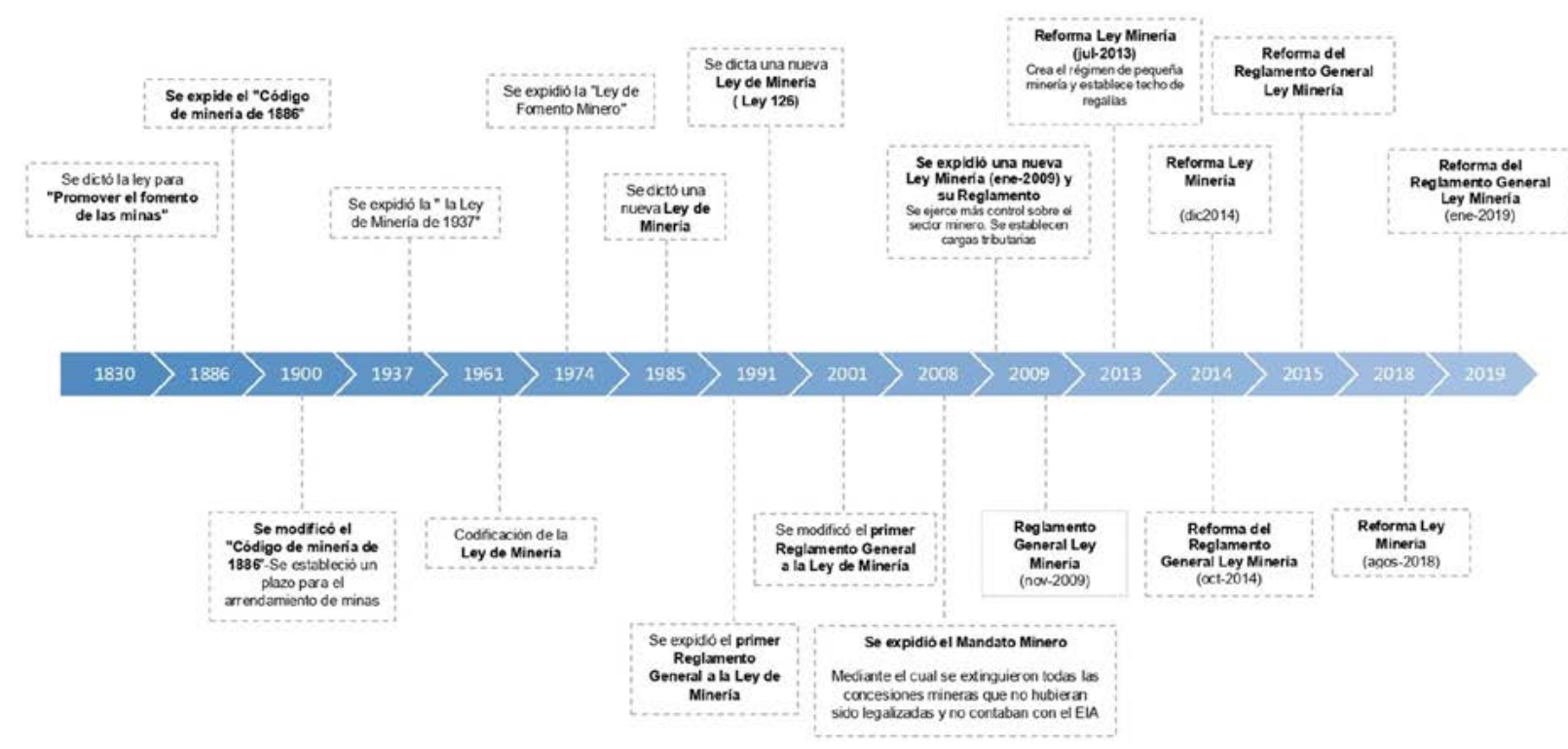

Figura 1. Regulaciones mineras en el Ecuador a través del tiempo (Morejón, 2012; Sandoval, 2001; Aillón Vásconez, 2016).

Figure 1. Mining regulations in Ecuador through time (Morejón, 2012; Sandoval, 2001; Aillón Vásconez, 2016). 
La principal problemática que presenta la explotación de recursos metálicos es la contaminación de los recursos naturales como el suelo, el recurso hídrico tanto superficial como subterráneo, además de los problemas relacionados a la existencia de escombreras y relaveras. De igual manera, el aprovechamiento de recursos no metálicos genera impactos como levantamiento de polvo, ruido, vibraciones y contaminación paisajística. Con el fin de minimizar los efectos que producen las actividades de pequeña y gran minería, se estableció como requisito la elaboración de un plan de impacto ambiental como mecanismo de control, en el cual se consideren las actividades de mitigación en todas las fases de la actividad minera como la de exploración, explotación y cierre de actividades. Anteriormente, existían cuatro tipos de categorización del impacto ambiental: (1) impactos no significativos que sólo necesitaban del registro ambiental para la realización de actividades mineras,

(2) impactos bajos declarados en una ficha ambiental, (3) impactos medios donde la declaración del impacto ambiental era compulsiva, y (4) impactos altos donde el estudio de impacto ambiental era un requisito para el otorgamiento de licencias. Este sistema de escasa aplicación práctica fue reemplazado por dos mecanismos sencillos conocidos como el registro ambiental para actividades de impacto ambiental moderado y obtención de la licencia ambiental para actividades que generen un alto impacto en el medio ambiente. El ente regulador de las licencias ambientales es el Ministerio del Ambiente (MAE) en calidad de su máxima autoridad nacional.

Con respecto al licenciamiento de materiales no metálicos o de construcción, el ente encargado son los municipios que se encuentren acreditados ante el MAE o las direcciones provinciales del MAE.

La reforma a la Ley de Minería procura reducir los tiempos de obtención de éstas licencias para asegurar que las empresas u organizaciones interesadas en las concesiones mineras presenten sus estudios de impacto ambiental en un formato no susceptible a cambios de fondo. De esta forma, se agilizaría el proceso de obtención de licencias, lo cual en la actualidad es una de los principales problemas, ya que está asociado a los cambios frecuentes de las estructuras organizativas, autoridades y del personal del Viceministerio de Minas, ARCOM, y el Instituto de Investigación Geológico y Energético.

\section{Contexto social}

El sector minero en el Ecuador crea un debate de ideologías debido a la escasa información sobre los diferentes tipos de minería, métodos de exploración, explotación, beneficios, limitaciones y experiencias negativas asociadas a actividades anti-técnicas de esta actividad. Adicionalmente, la escasa planificación con pertinencia al ordenamiento territorial ha afectado el uso de los diferentes tipos de suelo.
Por este motivo, es prioritario que el sector fomente credibilidad y confianza acercándose a la comunidad. En el Ecuador, por ejemplo, se realizan cuatro acciones orientadas a desarrollar el bienestar comunitario y su economía. Esto se traduce en obligaciones económicas por ley, que corresponde a la inversión en el país a través del pago de regalías, impuestos y utilidades. Contratación de personal local y nacional. Desarrollo de proyectos de emprendimiento orientados al sector agropecuario y de alimentos. Realización de actividades locales que incluyen capacitación, fiestas, inversión en educación y vías.

Actualmente, el Ecuador registra minería a gran escala desarrollada por cinco empresas mineras de las cuales, dos participaron en el informe denominado "Responsible Mining Index". Este informe comprendió seis áreas temáticas: (1) desarrollo económico, (2) conducta empresarial, (3) gestión del ciclo de vida, (4) bienestar comunitario, (5) condiciones de trabajo, y (6) responsabilidad medioambiental.

Dentro del desarrollo económico se evidenció que existe escasa información sobre la empleabilidad de las poblaciones locales entorno a las labores de explotación minera. Para ejemplificar, la minería industrial generó alrededor de 5200 empleos directos, la pequeña minería 4614 empleos y la minería artesanal 3332 empleos. Sin embargo, a pesar de que en el Art. 75 de la Ley de Minería se establece como requisito que el $80 \%$ de personal contratado debe corresponder a ciudadanos ecuatorianos, éste porcentaje se no declara en las cifras oficiales. A pesar de las reformas a la Ley de Minería, el tema de transparencia corporativa y el libre acceso a la información que éstas empresas manejan se encuentra en una etapa inicial. Por ejemplo, la declaración de utilidades reducidas puede constituir una herramienta para evasión fiscal, así como la declaración de concentraciones de mineral (ley) y producción. Otra problemática del sector minero de la cual se posee escasa información es la seguridad y salud ocupacional ya que no existe transparencia en el reporte de accidentes laborales e índice de mortandad entre los trabajadores del sector (García, E. 2016).

A pesar de los esfuerzos para mejorar la Ley de Minería, existen escasos mecanismos que faciliten la gestión del ciclo de vida de un proyecto minero. Se ha identificado que la falta de información no sólo comprende aspectos técnicos sino también de garantías financieras y legales en caso de que las actividades mineras culminen de forma anticipada. Esto en principio debería estar tipificado en los planes de estudios de impacto ambiental con el fin de mitigar los posibles riesgos para las empresas. Además, la inclusión de estos aspectos minimizaría el impacto (desempleo) en las comunidades que realizan actividades económicas secundarias en las inmediaciones de las empresas mineras.

El tema de responsabilidad social que impacta directamente al bienestar comunitario ha sido regulado hasta la actualidad por la Empresa Pública de Desa- 
rrollo Estratégico ECUADOR ESTRATEGICO EP. Una suma de aproximadamente $\$ 120$ millones de dólares ha sido recaudada hasta el año 2017 de la cual el $8 \%$ ha sido destinado a obras en beneficio a las zonas influenciadas por las actividades mineras. Entre las principales obras que se han entregado constan: un camal municipal contribuyendo al fortalecimiento de la salubridad del sector, al realizarse las actividades de faenamiento idóneamente. El diseño y construcción de un sistema de agua potable benefició alrededor de 415 habitantes de sectores rurales del país fomentando uno de los objetivos del Plan Nacional de Desarrollo 2017-2021 “Toda una Vida" del Ecuador al contribuir con el mejoramiento de la calidad de vida de la población, especialmente la más vulnerable.

A pesar de que la información sobre contratación, empleo, salario, seguridad social, y promoción de los trabajadores en las empresas no se encuentra disponible. Se reporta que el Ecuador ha trabajado en temas de capacitación (invirtiendo cerca de $\$ 4$ millones de dólares) con organismos internacionales como el Programa de las Naciones Unidas (PNUD) para fomentar una cultura de uso responsable de químicos empleados en los procesos extractivistas de la actividad minera. Uno de los ejes fundamentales es adoptar métodos que permitan reducir tanto el uso de contaminantes orgánicos persistentes y el mercurio. Este proyecto impulsado en conjunto con el PNUD tiene como objetivo final la concienciación y divulgación de los resultados de este proyecto. También, el Ecuador ha formado alianzas estratégicas con otros países del continente americano, europeo y asiático en temas de responsabilidad social (Canadá), conocimiento técnico-científico (Japón), manejo de recursos hídricos (Chile), normativa y tributación (Alemania), capacitación (USA y Corea del Sur), cooperación (México) e intercambio de experiencias (Perú y Colombia). Lo cual facilitará el desarrollo sostenible de la minería respetando aspectos técnicos, sociales, legales y ambientales de cara a enfrentar la realidad minera del país.

Es importante reportar que las empresas mineras a gran escala en Ecuador trabajan en proyectos de emprendimiento dirigido a mujeres, a la población indígena y/o local, orientados principalmente a temas agropecuarios y de alimentos. Sin embargo, existe una extensa labor por realizar, especialmente, con el tema del jancheo, el cual es una ocupación realizada mayoritariamente por el sector femenino. Las jancheras, son mujeres cuyo trabajo consiste en recolectar rocas mineralizadas (con presencia de minerales con interés económico) en las escombreras, el cual es el material desechado por las empresas mineras. Este grupo laboral es de gran importancia en algunos sectores mineros para el sustento de sus hogares, existen además algunas experiencias sobre la asociatividad con la finalidad de mejorar sus condiciones laborales y de desarrollo económico como un mecanismo para la inclusión de las mujeres en el sector minero (Yánez $\mathrm{Paz}, 2018)$.
Desafortunadamente, el jancheo también empleaba mano de obra infantil, siendo uno de los grandes problemas del sector minero (IPEC SUDAMERICA, 2002). Los datos del informe de la Línea Base de Trabajo Infantil en la Minería Artesanal del Oro en Ecuador mostraron que $75 \%$ de los niños trabajadores tenían más de 10 años de edad, de los cuales $65 \%$ eran niños y $35 \%$ niñas. En la zona de Chinapintza esta realidad era aún más alarmante ya que niños de edades entre 5 y 9 años conformaban la mano de obra. Entre las actividades en las cuales los niños eran empleados constan: (i) el jancheo, (ii) canaloneros que corresponde a la actividad de recuperación de material en relaves no usados por las empresas dispuesto en quebradas y se recoge mediante platoneo, (iii) mina donde los niños se desempeñaban como ayudantes de los barrenadores, transportistas, y cargadores, y (iv) plantas de beneficio donde el trabajo infantil consistía en introducir rocas en molinos, chanchas, procesos de amalgamación, transportación y lavado de recipientes.

\section{Actividad minera en el Ecuador}

Desde el inicio de la presidencia de Rafael Correa se consideró a la minería como un sector estratégico y se promovió al Ecuador como un país con gran potencial minero, a pesar de no contar con estudios de exploración a nivel nacional, se desarrollaron expectativas en base a las experiencias y potencial minero de países cercanos como Perú, Bolivia y Chile. El desarrollo del sector minero ha sido esperado desde el año 2012 por el Gobierno, algunas comunidades, Empresas Mineras, y Universidades. Sin embargo, este proceso tuvo retrasos ocasionados por las negociaciones para los contratos de explotación, lo que ha ocasionado que la explotación de algunas empresas mineras se proyecte para finales del año 2019.

En el año 2012 se indicaba la necesidad de incrementar el número de graduados de las carreras de ingeniería de minas y geología para satisfacer una futura demanda esperada del sector minero, y fueron altas las expectativas que algunas universidades reabrieron las carreras de ingeniería de minas ante las expectativas esperadas, muchas de estas universidades tuvieron estas carreras cerradas por la baja cantidad de estudiantes que tenían, lo cual representaba un costo elevado para las universidades.

En el 2010 inicia la negociación de los contratos mineros de explotación con los proyectos Mirador, de la empresa china Ecuacorriente, y Fruta del Norte bajo la operación de Kinross Aurelian. En ese momento el Ministerio de Sectores Estratégicos esperaba que los contratos se firmen antes del 2011 y se hablaba que a finales de 2012 podía iniciarse la explotación minera. Los puntos críticos a discusión para la firma de contratos fueron: porcentaje de regalías, repartición de utilidades extraordinarias, los gastos deducibles del Impuesto a la Renta y el marco de protección para los inversionistas. 
En el 2012 se firmó el primer contrato de explotación minera a gran escala en Ecuador, correspondiente al proyecto Mirador. En ese mismo año la empresa inció el pago de regalías anticipadas con la finalidad de ser invertidos en proyectos de desarrollo social y productivo de las zonas de influencia del proyecto minero.

En el 2013 la minera Kinross abandonó el proyecto Futa del Norte porque no se consiguió una negociación de los contratos de explotación minera en lo que son las utilidades extraordinarias y de protección de las inversiones, En el 2016, la minera canadiense Lundin Gold anunció que ha firmado el contrato de explotación minera para su proyecto de Fruta del Norte. El pago de regalías anticipadas por el proyecto fue de USD 65 millones.

Es decir, \$165 millones de regalías anticipadas entre estos dos proyectos mineros, que fueron usados el $60 \%$ para proyectos de inversión social que fueron manejados por la Empresa Pública Ecuador Estratégico en la provincia de Zamora Chinchipe y el $40 \%$ para el Gobierno Central.

La Fig. 2 muestra los tipos de concesión minera distribuidos en material metálico, no metálico y material de construcción. Los permisos para la extracción de materiales metálicos se encuentran distribuidos en las provincias de Zamora Chinchipe, Loja, El Oro, Morona Santiago, Azuay, Napo, Bolívar, Cotopaxi, Sucumbíos e Imbabura resaltados en color amarillo en el mapa. Por otro lado, los minerales no metálicos se encuentran distribuidos en la sierra del Ecuador, así como en las zona costera y oriental del país. Los recursos no

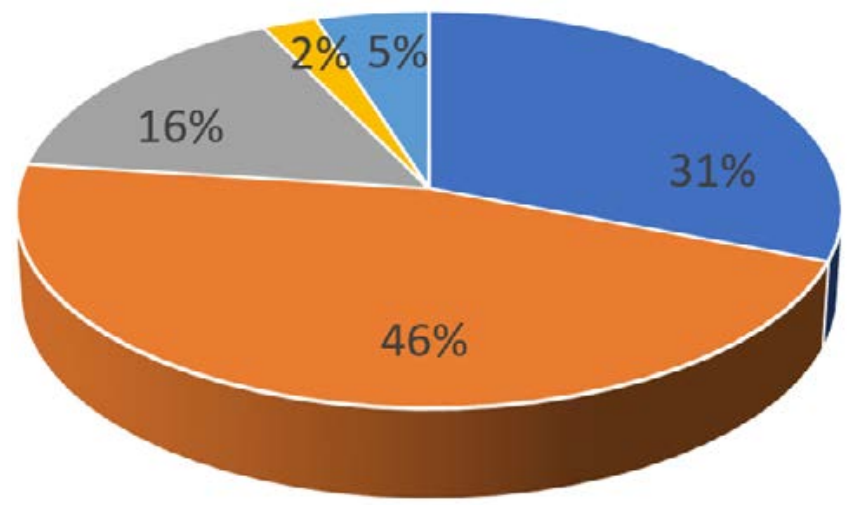

- Concesiones mineras

a Permisos de minería artesanal

- Libres de Aprobechamiento

- Plantas de Beneficio

- Licencias de comercialización

Figura 2. Tipo de concesión minera.

Figure 2. Type of mining concession. metálicos incluyen 3 minerales de mayor representatividad que son la caliza, arcillas, piedra pómez y en menor proporción el mármol, sílice, dióxido de carbono, caolín, zeolita, feldespato, yeso y bentonita.

En la actualidad dentro del país existen 4760 derechos mineros debidamente registrados (Art. 17 Ley de Minería. - Derechos mineros. - Por derechos mineros se entienden aquellos que emanan tanto de los títulos de concesiones mineras, contratos de explotación minera, licencias y permisos, como de las autorizaciones para instalar y operar plantas de beneficio, fundición y refinación, y de las licencias de comercialización). La Fig. 3 muestra que el $46 \%$ corresponde a permisos para realizar minería artesanal, evidenciando que pese a los esfuerzos del gobierno ecuatoriano y de las medidas adoptadas para impulsar una minería con responsabilidad técnica, social, legal y ambiental, el tipo de minería mayormente practicada en el país es del tipo artesanal. La minería artesanal metálica constituye el sector productivo que genera considerables fuentes de empleo y sustento, principalmente en zonas rurales. Sin embargo, este tipo de minería presenta problemas técnico-ambientales, de seguridad y salud ocupacional debido a que las condiciones de trabajo son precarias y con nula aplicación de tecnologías.

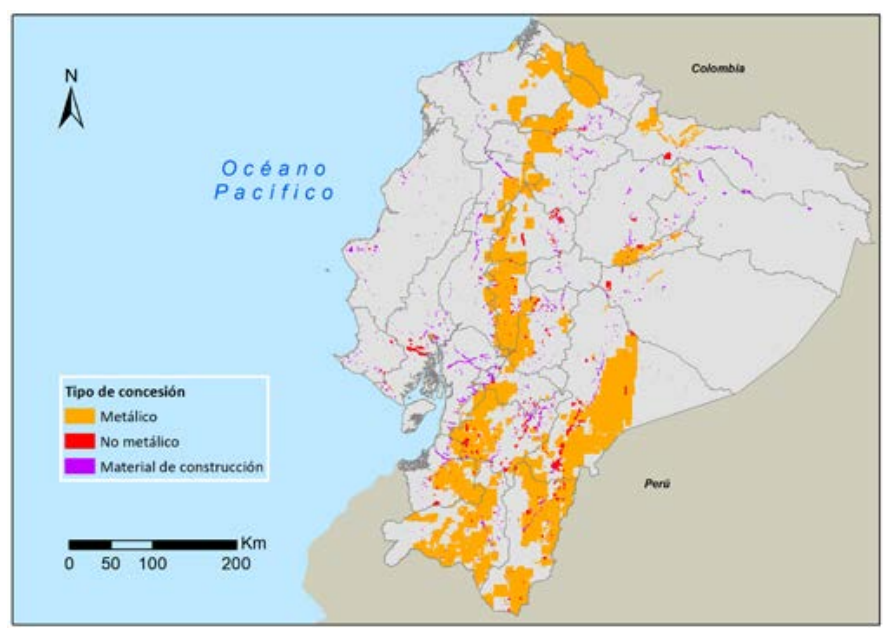

Figura 3: Derechos mineros en el Ecuador (Agencia de Regulación y Control Minero, 2019a).

Figure 3. Mining rights in Ecuador (Mining Regulation and Control Agency, 2019a).

El 54\% restante de la actividad minera se distribuye en concesiones de pequeña minería (31\%), libre aprovechamiento (16\%), licencias de comercialización $(5 \%)$ y el sólo el $2 \%$ corresponde a licencias otorgadas a plantas de beneficio. Acorde a los datos de la Agencia de Regulación y Control Minero (ARCOM), las plantas de beneficio se concentran especialmente en las provincias de Azuay en la parroquia de Camilo Ponce Enríquez y en El Oro dentro de la parroquia de Portovelo. 
LaTabla 2 muestra un resumen de las ciudades que poseen el mayor número de concesiones mineras. Siendo Zamora (25\%), Machala y Cuenca (13\% respectivamente) las tres ciudades de mayor intensidad de labor minera. después de finalizar la fase de exploración. Estos proyectos poseen dos tipos de minas, la de cielo abierto y la subterránea. Los principales metales explotados en estas concesiones son oro, plata y cobre con una estimación de reservas que varía desde 0.60 a 4.94

\begin{tabular}{|c|c|c|c|c|c|c|c|}
\hline $\begin{array}{l}\text { Coordinació } \\
\mathrm{n} \text { regional }\end{array}$ & $\begin{array}{l}\text { Concesione } \\
\mathrm{s} \text { mineras }\end{array}$ & $\begin{array}{l}\text { Permiso } \\
\text { s de } \\
\text { minería } \\
\text { artesanal }\end{array}$ & $\begin{array}{l}\text { Libres de } \\
\text { Aprovechamient } \\
0\end{array}$ & $\begin{array}{l}\text { Plantas } \\
\text { de } \\
\text { Benefici } \\
\text { o }\end{array}$ & $\begin{array}{l}\text { Licencias de } \\
\text { comercializació } \\
\mathrm{n}\end{array}$ & $\begin{array}{l}\text { Tota } \\
1\end{array}$ & $\%$ \\
\hline Zamora & 263 & 851 & 37 & 5 & 10 & 1166 & $24.50 \%$ \\
\hline Machala & 207 & 208 & 23 & 78 & 101 & 617 & $12.96 \%$ \\
\hline Loja & 92 & 452 & 53 & 0 & 3 & 600 & $12.61 \%$ \\
\hline Cuenca & 250 & 174 & 59 & 27 & 56 & 566 & $11.89 \%$ \\
\hline Guayaquil & 123 & 56 & 135 & 0 & 41 & 355 & $7.46 \%$ \\
\hline Ibarra & 101 & 39 & 136 & 0 & 8 & 284 & $5.97 \%$ \\
\hline Macas & 216 & 244 & 53 & 0 & 0 & 513 & $10.78 \%$ \\
\hline Riobamba & 138 & 70 & 129 & 2 & 3 & 342 & $7.18 \%$ \\
\hline Tena & 78 & 102 & 125 & 0 & 12 & 317 & $\begin{array}{l}6.66 \% \\
100.00\end{array}$ \\
\hline Total & 1468 & 2196 & 750 & 112 & 234 & 4760 & $\%$ \\
\hline
\end{tabular}

Tabla 2. Derechos mineros registrados en el Ecuador.

Table 2. Mining rights registered in Ecuador.

La Fig. 4 muestra que la explotación de materiales de construcción en el Ecuador se realiza a través de concesiones artesanales (representadas por los puntos lila), donde la mayo explotación se concentra en materiales como la piedra, grava y arena.

La Tabla 3 muestra los cinco principales proyectos mineros estratégicos que se realizan en el país, llamados Loma Larga, San Carlos Panantza, Mirado, Río Blanco y Fruta del Norte. Las actividades de producción están programadas a comenzar en el año 2021

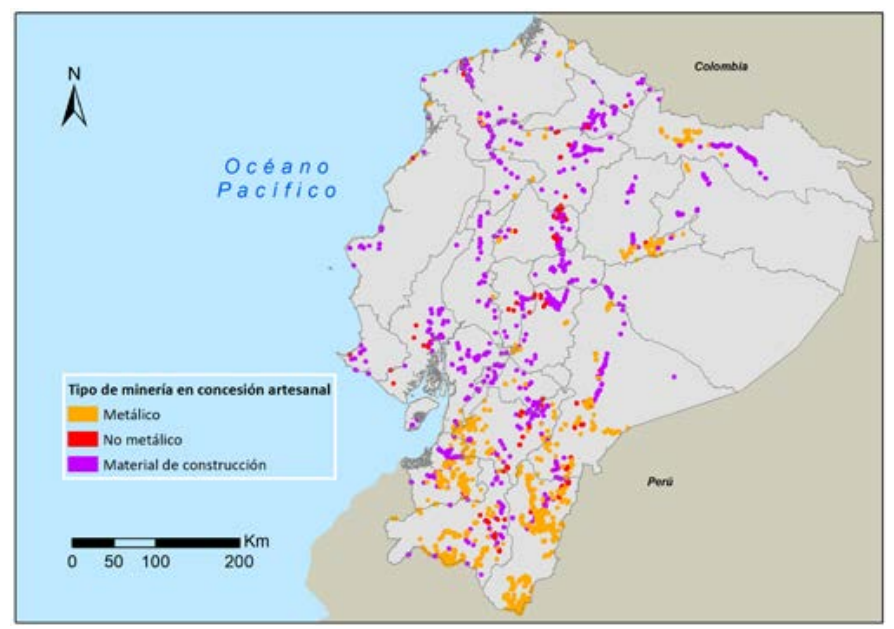

Figura 4. Tipo de minería en concesiones artesanales. Figure 4. Type of mining in artisanal concessions. millones de onzas. La estimación del promedio de regalías para el país es de $\$ 75$ millones de dólares y la generación de empleo se estima que es de alrededor 12000 personas (trabajo directo e indirecto).

Existen seis proyectos denominadas de segunda generación los cuales se denominan Llumiragua, La Plata, Cangrejos, Cascabel, Curipamba, y Ruta del Cobre (ver Fig. 5). El proyecto Cascabel concesionado a la empresa SolGold PLC se posiciona en el ranking mundial como una de las reservas más

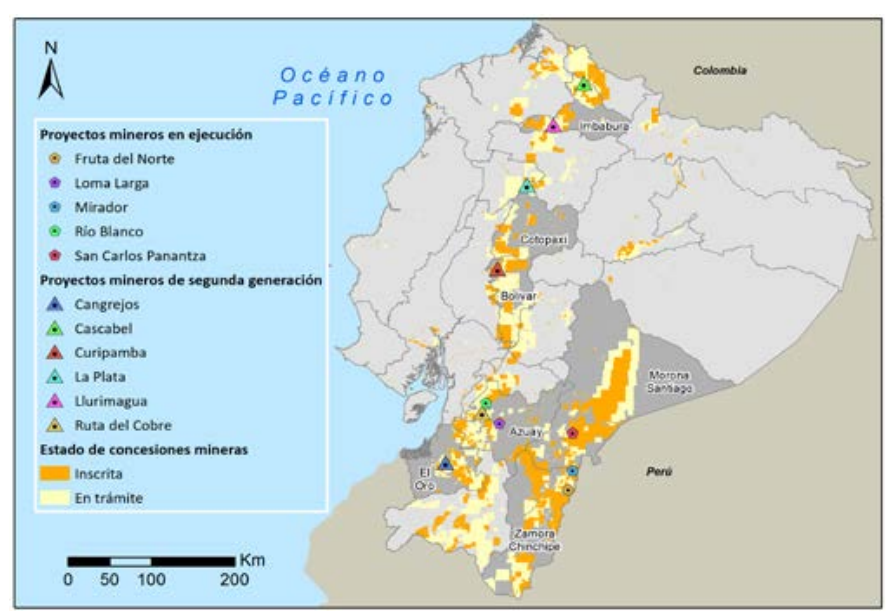

Figura 5. Ubicación de proyectos mineros estratégicos y de segunda generación (recursos metálicos).

Figure 5. Location of strategic and second-generation mining projects (metallic resources). 
Estupiñan, R., et al, 2021. La minería en Ecuador. Pasado, presente y futuro, 132 (4): 533-549

\begin{tabular}{|c|c|c|c|c|c|}
\hline Proyecto: & Loma Larga & $\begin{array}{l}\text { San Carlos } \\
\text { Panantza } \\
\end{array}$ & Mirador & Río Blanco & Fruta del norte \\
\hline Concesionario: & $\begin{array}{l}\text { INV Metals } \\
\text { (INV } \\
\text { Minerals } \\
\text { Ecuador S.A.) }\end{array}$ & $\begin{array}{l}\text { Explorcobre } \\
\text { S.A. (EXSA) }\end{array}$ & $\begin{array}{l}\text { Ecuacorriente } \\
\text { S.A. }\end{array}$ & Ecuagoldmining & Lundin Gold \\
\hline $\begin{array}{l}\text { Información } \\
\text { disponible en } \\
\text { página web }\end{array}$ & $\begin{array}{l}\text { Acceso } \\
\text { público a la } \\
\text { información }\end{array}$ & $\begin{array}{l}\text { Presenta } \\
\text { información } \\
\text { escasa }\end{array}$ & $\begin{array}{l}\text { Presenta } \\
\text { información } \\
\text { escasa }\end{array}$ & $\begin{array}{l}\text { Acceso público a la } \\
\text { información }\end{array}$ & $\begin{array}{l}\text { Acceso público } \\
\text { a la } \\
\text { información }\end{array}$ \\
\hline Ubicación: & Azuay & $\begin{array}{l}\text { Morona } \\
\text { Santiago }\end{array}$ & $\begin{array}{l}\text { Zamora } \\
\text { Chinchipe }\end{array}$ & Azuay & $\begin{array}{l}\text { Zamora } \\
\text { Chinchipe }\end{array}$ \\
\hline Exploración & $\begin{array}{l}\text { Exploración } \\
\text { inicial 2003- } \\
2013 \\
\text { Exploración } \\
\text { avanzada } \\
\text { desde } 2013 \text { a } \\
2019\end{array}$ & $\begin{array}{l}\text { Las primeras } \\
\text { exploraciones } \\
\text { iniciaron en } \\
1990 \text { (duración } \\
\text { de } 5 \text { años) }\end{array}$ & $\begin{array}{l}\text { Exploración de } \\
1994 \text { al } 2005\end{array}$ & $\begin{array}{l}\text { Exploración } \\
\text { avanzada del } 2004 \\
\text { al } 2015\end{array}$ & $\begin{array}{l}\text { Exploración } \\
\text { inicial } 2001 \text { a } \\
2002 \\
\text { Exploración } \\
\text { avanzada } 2003 \\
\text { a } 2019\end{array}$ \\
\hline Vida del proyecto: & $\begin{array}{l}12 \text { años desde } \\
\text { inicio }\end{array}$ & $\begin{array}{l}25 \text { años } \\
\text { estimado }\end{array}$ & $\begin{array}{l}27 \text { a } 30 \text { años } \\
\text { desde inicio de } \\
\text { producción }\end{array}$ & $\begin{array}{l}11 \text { años desde el } \\
\text { inicio de la } \\
\text { producción }\end{array}$ & $\begin{array}{l}15 \text { años desde } \\
\text { inicio de } \\
\text { producción }\end{array}$ \\
\hline Tipo de mina: & Subterránea & $\begin{array}{l}\text { Mina a cielo } \\
\text { abierto }\end{array}$ & A cielo abierto & Subterránea & Subterránea \\
\hline $\begin{array}{l}\text { Inicio de } \\
\text { producción: }\end{array}$ & $\begin{array}{l}\text { Primer } \\
\text { trimestre de } \\
2021\end{array}$ & N/D & $\begin{array}{l}\text { Cuarto trimestre } \\
\text { de } 2019\end{array}$ & $\begin{array}{l}2018 \text { (suspendido } \\
\text { por orden judicial) }\end{array}$ & $\begin{array}{l}\text { Cuarto } \\
\text { trimestre de } \\
2019\end{array}$ \\
\hline Situación actual & $\begin{array}{l}\text { Se encuentra } \\
\text { en fase de } \\
\text { exploración } \\
\text { avanzada y } \\
\text { evaluación } \\
\text { económica }\end{array}$ & $\begin{array}{l}\text { Actividades } \\
\text { suspendidas por } \\
\text { conflictividad } \\
\text { social }\end{array}$ & $\begin{array}{l}\text { Construcción y } \\
\text { producción en } \\
\text { diciembre } 2019\end{array}$ & $\begin{array}{l}\text { Paralizado por } \\
\text { consulta }\end{array}$ & $\begin{array}{l}\text { Construcción y } \\
\text { en producción } \\
\text { para finales de } \\
2019\end{array}$ \\
\hline $\begin{array}{l}\text { Reservas de } \\
\text { minera }\end{array}$ & $\begin{array}{l}\text { Oro } 2,2 \\
\text { millones de } \\
\text { onzas }\end{array}$ & $\begin{array}{l}\text { Cobre } 3,05 \\
\text { millones de } \\
\text { toneladas }\end{array}$ & $\begin{array}{l}\text { Cobre } 3,18 \\
\text { millones de } \\
\text { toneladas }\end{array}$ & $\begin{array}{l}\text { Oro } 0,60 \text { millones } \\
\text { de onzas }\end{array}$ & $\begin{array}{l}\text { Oro } 4,94 \\
\text { millones de } \\
\text { onzas }\end{array}$ \\
\hline Inversión 2018: & $\begin{array}{l}\text { USD 4,03 } \\
\text { millones }\end{array}$ & $\begin{array}{l}\text { USD 2,3 } \\
\text { millones (hasta } \\
\text { el tercer } \\
\text { trimestre) }\end{array}$ & $\begin{array}{l}\text { USD 193,20 } \\
\text { millones }\end{array}$ & USD 4,12 millones & $\begin{array}{l}\text { USD 238,21 } \\
\text { millones }\end{array}$ \\
\hline $\begin{array}{l}\text { Regalías } \\
\text { anticipadas: }\end{array}$ & N/D & $\mathrm{N} / \mathrm{D}$ & $\begin{array}{l}\text { USD } 85 \\
\text { millones de } \\
\text { dólares }\end{array}$ & $\mathrm{N} / \mathrm{D}$ & $\begin{array}{l}\text { USD } 65 \\
\text { millones }\end{array}$ \\
\hline Empleos actuales: & 216 & $\mathrm{~N} / \mathrm{D}$ & $\begin{array}{l}\text { Empleos } \\
\text { directos: } 2330 \\
\text { Empleos } \\
\text { indirectos: } 6990\end{array}$ & N/D & $\begin{array}{l}3000 \\
\text { empleados } \\
\text { aprox. }\end{array}$ \\
\hline Minerales: & $\begin{array}{l}\text { cobre, oro y } \\
\text { plata }\end{array}$ & Cobre & $\begin{array}{l}\text { cobre, oro y } \\
\text { plata }\end{array}$ & Cobre, plata, oro & Oro, plata \\
\hline
\end{tabular}

Tabla 3. Proyectos mineros en ejecución- Proyectos Estratégicos (Dirección Nacional de Síntesis Macroeconómica, 2019, Ministerio de Energía y Recursos Naturales no Renovables, 2019, y Drobe, 2007).

Table 3. Mining projects in execution - strategic projects (National Directorate of Macroeconomic Synthesis, 2019, Ministry of Energy and Non-Renewable Natural Resources, 2019, and Drobe, 2007).

grandes en Ag, tercera en $\mathrm{Au}(23$ millones de onzas) y sexta de cobre (10,9 millones de toneladas de cobre). Ésta concesión se encuentra ubicada en la provincia de Imbabura y se estima que el tiempo de vida del proyecto es de 66 años. Actualmente, se encuentra en la etapa de evaluación económica preliminar y se proyecta que las actividades de producción comiencen en el año 2020. 


\begin{tabular}{|c|c|c|c|c|c|c|}
\hline Proyecto & Llumiragua & La Plata & Cangrejos & Cascabel & Curipamba & $\begin{array}{l}\text { Ruta del } \\
\text { cobre }\end{array}$ \\
\hline $\begin{array}{l}\text { Operado por } \\
\text { la empresa: }\end{array}$ & $\begin{array}{l}\text { Corporación del } \\
\text { cobre de Chile } \\
\text { (Codelco) y } \\
\text { Empresa Nacional } \\
\text { Minera de Ecuador } \\
\text { (Enami EP) }\end{array}$ & $\begin{array}{l}\text { La Plata } \\
\text { S.A (parte } \\
\text { de Toachi } \\
\text { Mining Inc) }\end{array}$ & $\begin{array}{l}\text { Odin } \\
\text { Mining del } \\
\text { Ecuador } \\
\text { S.A. (parte } \\
\text { de Lumina } \\
\text { Gold Corp) }\end{array}$ & $\begin{array}{l}\text { Exploraciones } \\
\text { Novomining } \\
\text { S.A. (parte de } \\
\text { SolGold PLC) }\end{array}$ & $\begin{array}{l}\text { Curiming } \\
\text { S.A. (parte } \\
\text { de Salazar } \\
\text { Resources } \\
\text { Limited) }\end{array}$ & $\begin{array}{l}\text { Ruta del } \\
\text { cobre (parte } \\
\text { de } \\
\text { Southerm } \\
\text { Copper } \\
\text { Corp) }\end{array}$ \\
\hline $\begin{array}{l}\text { Inversión } \\
\text { ejecutada en } \\
\text { 2018: }\end{array}$ & $\begin{array}{l}5,98 \text { millones de } \\
\text { dólares }\end{array}$ & $\begin{array}{l}0.20 \\
\text { millones de } \\
\text { dólares }\end{array}$ & $\begin{array}{l}0,91 \\
\text { millones de } \\
\text { dólares }\end{array}$ & $\begin{array}{l}22,15 \\
\text { millones de } \\
\text { dólares }\end{array}$ & $\begin{array}{l}0,62 \\
\text { millones de } \\
\text { dólares }\end{array}$ & $\begin{array}{l}0,41 \\
\text { millones de } \\
\text { dólares }\end{array}$ \\
\hline Fase & $\begin{array}{l}\text { Exploración } \\
\text { avanzada }\end{array}$ & $\begin{array}{l}\text { Exploración } \\
\text { avanzada }\end{array}$ & $\begin{array}{l}\text { Exploración } \\
\text { avanzada }\end{array}$ & $\begin{array}{l}\text { Exploración } \\
\text { avanzada }\end{array}$ & $\begin{array}{l}\text { Exploración } \\
\text { avanzada }\end{array}$ & $\begin{array}{l}\text { Exploración } \\
\text { avanzada }\end{array}$ \\
\hline Minerales: & $\mathrm{Cu}, \mathrm{Mo}$ & $\begin{array}{l}\mathrm{Cu}, \mathrm{Au}, \mathrm{Ag}, \\
\mathrm{Zn}, \mathrm{Pb}\end{array}$ & $\begin{array}{l}\mathrm{Cu}, \mathrm{Au}, \mathrm{Ag}, \\
\mathrm{Mo}\end{array}$ & $\mathrm{Cu}, \mathrm{Au}$ & $\begin{array}{l}\mathrm{Cu}, \mathrm{Au}, \mathrm{Ag}, \\
\mathrm{Zn}, \mathrm{Pb}\end{array}$ & $\mathrm{Cu}$ \\
\hline
\end{tabular}

Tabla 4. Proyectos mineros segunda generación en el Ecuador (Dirección Nacional de Síntesis Macroeconómica, 2019; y Ministerio de Energía y Recursos Naturales no Renovables, 2019).

Table 4. Second-generation mining projects in Ecuador (National Directorate of Macroeconomic Synthesis, 2019; and Ministry of Energy and Non-Renewable Natural Resources, 2019).

Adicionalmente, existen 3 proyectos que se encuentran en el portafolio disponible de la Empresa Nacional Minera. LaTabla 5 muestra que dos de dichos proyectos se encuentran en exploración inicial desde el 2012 y poseen la licencia ambiental. Los tipos de minerales que estas concesiones han planificado explotar consisten en caliza, $\mathrm{Au}, \mathrm{Ag}, \mathrm{Cu}, \mathrm{Mb}, \mathrm{Zn}$ y Pb. Éstas concesiones representan para el país una importante fuente de capital. gicos, de segunda generación y los que se encuentra en el portafolio de la Empresa Nacional Minera del Ecuador.

En el 2018, el ingreso total por conservación de patentes, utilidades y regalías mineras, contemplados en la Ley de Minería (Presidencia de la República, 2009) en los artículos 34, 67 y 93 fue de $\$ 54$ millones de dólares (Tabla 6 ), teniendo la mayor contribución lo recaudado por las regalías con un porcentaje de

\begin{tabular}{llll}
\hline Proyecto & Unacota & Sigchos & Pacto \\
\hline $\begin{array}{l}\text { Ubicación } \\
\text { Mineral }\end{array}$ & $\begin{array}{l}\text { Cotopaxi, Pujili, Zumbahua } \\
\text { Caliza }\end{array}$ & $\begin{array}{l}\text { Cotopaxi } \\
\text { Cobre, Oro, Plata }\end{array}$ & $\begin{array}{l}\text { Pichicncha, Quito } \\
\text { Oro, Molibdemos, Zinc, } \\
\text { Plata, Plomo, Cobre }\end{array}$ \\
$\begin{array}{l}\text { Superficie } \\
\text { Fase }\end{array}$ & $\begin{array}{l}\text { 2.747 hectáreas } \\
\text { Exploración inicial. } \\
\text { Desde el 2012 se inició la } \\
\text { exploración. }\end{array}$ & $\begin{array}{l}\text { 10.580 hectáreas } \\
\text { Exploración inicial } \\
\text { Desde el 2013 se inició la } \\
\text { evaluación }\end{array}$ & $\begin{array}{l}\text { Exploración Avanzada } \\
\text { Aprobada }\end{array}$ \\
$\begin{array}{l}\text { Licencia } \\
\text { ambiental } \\
\text { Inversión }\end{array}$ & USD 250.276,56 & USD 422.90,16 & Pendiente \\
\hline
\end{tabular}

Tabla 5. Portafolio de inversiones de la ENAMI 2019 (Empresa Nacional Minera, 2019a, 2019b).

Table 5. Investment portfolio of the ENAMI 2019 (National Mining Company of Ecuador, 2019a, 2019b).

\section{Contexto económico}

En los últimos 12 años, la participación de la minería en el PIB del Ecuador se ha incrementado del $0.17 \%$ (en 2007) al 0.32\% (en 2017). Debido a este porcentaje, la minería en el país no representa un sector estratégico al momento. Sin embargo, al finalizar el año 2020 se espera que este sector incremente su participación con los resultados de los proyectos mineros estraté-
$61 \%$ seguido de la conservación de patentes (33\%). En la Tabla 6 se observa el detalle de los ingresos recaudados.

A pesar que la mediana minería sólo cuenta con un proyecto de producción a cielo abierto llamado Cerro Verde y ubicado en la ciudad Loja (comunidad Célica), en los últimos 10 años, la pequeña y mediana minería han representado el $80 \%$ de la producción del sector. ARCOM y el Servicio de Rentas Internas (SRI) reporta- 
AÑO 2018

$\begin{array}{lrr}\text { RUBRO } & \text { VALOR U.S. \$ } & \% \\ \text { Recaudado S.R.I. patentes } & 17.916 .606,64 & 33,40 \% \\ \text { Patente gran escala } & 5.856 .581,00 & 10,92 \% \\ \text { Patente mediana minería } & 115.221,00 & 0,21 \% \\ \text { Patente pequeña minería } & 11.944 .804,64 & 22,27 \% \\ \text { Recaudado S.R.I. regalias } & 32.695 .864,66 & 60,95 \% \\ \text { Regalías gran escala } & 20.000 .000,00 & 37,28 \% \\ \text { Regalías pequeña minería } & 12.695 .864,66 & 23,67 \% \\ \text { Año 2017 pequeña minería } & 3.030 .316,22 & 5,65 \% \\ \text { TOTAL } & & 100,00 \%\end{array}$

Tabla 6. Aportación del sector minero en el Ecuador, en el año 2018 (Agencia de Regulación y Control Minero, 2019b).

Table 6. Contribution of the mining sector in Ecuador, in the year 2018 (Mining Regulation and Control Agency, 2019b).

ron que estos tipos de minería produjeron alrededor de \$13 millones de dólares en regalías y \$12 millones de dólares en patentes. Similarmente, los proyectos de gran minería aportaron al país más de $\$ 25$ millones de dólares a pesar de que sus proyectos no se encuentren en la fase de producción.

En la actualidad, el sector minero generó alrededor de \$ 42 millones de dólares en el primer cuatrimestre del 2019 como se detalle en la Tabla 7.

El Ministerio de Economía y Finanzas en junio del 2019, dio a conocer que se estima una inversión de $\$ 3.800$ millones de dólares hasta el 2021, de la cual $42 \%$ corresponde a los cinco proyectos estratégicos en ejecución (Mirador, Fruta del Norte, Loma Larga, Río Blanco y San Carlos Panantza). Se espera que de los proyectos de subasta y remate se obtengan $\$ 1250$ millones, seguidos de los proyectos de segunda generación que generarían \$ 754 millones de dólares a pesar de encontrarse en etapas primeras de exploración. Se proyecta que los proyectos de pequeña minería generen más de $\$ 160$ millones de dólares. El gobierno ecuatoriano también apuesta por las ventas al exterior que generarían \$ 3660 millones de dólares, constituyendo una de las exportaciones no petroleras más importantes de la nación. De esta forma, el sector minero crecería del $0.32 \%$ del PIB a una cifra del $4 \%$ en el 2021. Este porcentaje de ganancia serán destinados a fortalecer la inversión social en sectores prioritarios y vulnerables del estado.

\section{Diagnóstico}

La primera Ley de Minería en 1937 estuvo motivada por el auge minero de la época, donde los principales yacimientos estaban ubicados Nambija, Guayzimi, Chinapintza, Ponce Enríquez, Zaruma, Portovelo.

\begin{tabular}{lcc}
\hline & AÑO 2019 & \\
RUBRO & VALOR U.S. \$ & $38,93 \%$ \\
\hline Recaudado S.R.I. patentes & $16.274 .077,27$ & $11,24 \%$ \\
Patente gran escala & $4.700 .110,71$ & $0,47 \%$ \\
Patente mediana minería & $196.172,60$ & $27,21 \%$ \\
Patente pequeña minería & $11.377 .793,96$ & $52,61 \%$ \\
Recaudado S.R.I. regalias & $21.994 .465,88$ & $35,88 \%$ \\
Regalías gran escala & $15.000 .000,00$ & $0 \%$ \\
Regalía mediana minería & 0,00 & $16,73 \%$ \\
Regalías pequeña minería & $6.994 .465,88$ & \\
Utilidades mineras & & $8,47 \%$ \\
Año 2018 pequeña minería & $3.539 .040,92$ & $100,00 \%$ \\
TOTAL & $41.807 .584,07$ & \\
\hline
\end{tabular}

Tabla 7. Aportación del sector minero en el Ecuador, en el año 2019 (Banco Central del Ecuador, 2019). Table 7. Contribution of the mining sector in Ecuador, in the year 2019 (Central Bank of Ecuador, 2019). 
En el año 2009 el Cierre de minas fue incorporado como una fase de la actividad minera en la Ley de Minería, para garantizar la prevención, control y mitigación de los potenciales impactos negativos de la actividad. En el 2009 se define lo que es Minería artesanal, pequeña minería, mientras que las definiciones de la mediana y minería a gran escala son incorporadas en las reformas del año 2013.

En la Ley de Minería del 2009 se faculta a la autoridad única del agua para autorizar a los concesionarios mineros el aprovechamiento del agua para sus actividades. En 1972 se crea la primera Ley de Aguas y en el 2014 se expide la nueva Ley Orgánica de Recursos Hídricos, Usos y Aprovechamiento del Agua donde se ha implementado un proceso participativo para las Autorizaciones de Uso y Aprovechamientos, garantizando los derechos y responsabilidades de los usuarios del agua.

En el 2008 se reconoció los derechos de la Naturaleza en la Constitución, lo cual fue aplaudido por otros países y en el Ecuador, sin embargo, distintos grupos sociales manifestaron su desacuerdo con el artículo de las áreas protegidas; Se prohíbe la actividad extractiva de recursos no renovables en áreas protegidas. Excepcionalmente dichos recursos se podrán explotar a petición fundamentada de la Presidencia de la República, y previa declaratoria de interés nacional por parte de la Asamblea Nacional, de conformidad a lo determinado en el artículo 407 de la Constitución de la República del Ecuador; indicando que este artículo se contrapone con lo señalado en la Constitución sobre los derechos de la naturaleza.

La minería es considerada por el Gobierno como uno de los principales sectores estratégicos, y se lo incluye como uno de los puntos primordiales para el desarrollo económico del país, con la proyección de que los grandes proyectos mineros aporten de forma significativa al PIB, para no contar con la dependencia económica de un solo producto.

Actualmente los productos que aportan al PIB en el Ecuador son: camarón, petróleo, banano, café, cacao; donde el sector petrolero en los últimos años tuvo una baja de su valor agregado bruto (VAB), mientras que el sector no petrolero presentó un alza de su VAB. El aporte de la minería al PIB entre 1980 a 2018 ha sido entre $0.1 \mathrm{a} 0.5 \%$, y se espera que los proyectos a gran escala incrementen este aporte hasta el 4\% en el 2021.

Los titulares de pequeña minería pagarán por regalía, el $3 \%$ de las ventas del mineral principal y los minerales secundarios. Mientras para el concesionario minero deberá pagar una regalía equivalente a un porcentaje sobre la venta del mineral principal y los minerales secundarios, no menor al $5 \%$ sobre las ventas y, para el caso del oro, cobre y plata, no mayor al $8 \%$, adicional al pago correspondiente del impuesto a la renta; del porcentaje de utilidades atribuidas al Estado conforme esta ley (Asamblea Nacional, 2018). En la Ley de Fomento Minero de 1974 las regalías eran de hasta el $16 \%$ y en la Ley de 1985 y 1991 eran del 3\% de regalías.
El Ecuador se ha caracterizado por el aprovechamiento principalmente de materiales de construcción y no metálicos, y en recursos metálicos se ha concentrado su explotación en el oro. Actualmente la explotación de recursos metálicos se ha diversificado en los proyectos a gran escala: oro, cobre, plata, zinc, plomo, y molibdeno.

La minería artesanal que explota no metálicos y materiales de construcción tiene dificultades para cubrir los costos de la explotación, asesoría técnica, permisos, y procesos legales, además de los problemas para la comercialización que limita sus ingresos económicos.

La medición del impacto económico tiene limitaciones debido a la escasa información del sector minero, relacionados a: pago de impuestos, regalías, inversión de regalías (inversión local en proyectos de inversión social y en el Gobierno Central), empleabilidad, cadenas de suministros inclusivas, gobernanza de los recursos y transparencia.

Es imprescindible garantizar las condiciones de seguridad y salud en el trabajo en el sector minero debido a que es considerado entre los trabajos peligrosos por la Organización Internacional del Trabajo. Actualmente, en el país no se cuenta con una cultura de reportar los accidentes y existe un limitado acceso a la información sobre accidentes en el sector minero.

La explotación superficial ha estado orientada al aprovechamiento de recursos no metálicos y materiales de construcción, entre los principales problemas de seguridad laboral están concentrados en riesgos físicos y ergonómicos, por lesiones, exposición solar y esfuerzo físico durante la explotación, además del limitado uso de equipos de protección personal.

La explotación subterránea a estado orientada hacia el aprovechamiento de recursos metálicos, entre los principales problemas de seguridad laboral están: riesgos físicos principalmente por caídas de rocas, químicos por gases tóxicos y ergonómicos.

Los métodos de los procesos de recuperación mineral han evolucionado con la finalidad de reducir el impacto ambiental y mejorar las condiciones de salud laboral, estos procesos iniciaron con la amalgamación que presenta alta toxicidad, sin embargo todavía existe países de América Latina que siguen usando este proceso, entre ellos la minería artesanal en: Colombia, Perú, Bolivia y Ecuador; posteriormente se implementaron procesos de cianuración y flotación, con la finalidad de optimizar la recuperación del mineral y reducir el impacto ambiental.

El sector de minería metálica presenta un mayor rechazo de la sociedad debido a potenciales impactos ambientales, originados principalmente en las voladuras (presencia de gases tóxicos), almacenamientos de relaves, en la infiltración y descarga de efluentes a fuentes de agua superficial y subterránea (turbidez y presencia de metales). Los proyectos a gran escala han presentado alta discrepancia entre los actores locales debido al temor de una posible afectación ambiental en las futuras explotaciones. 
En relación con el sector de minería no metálica presenta una mayor aceptación de la sociedad, donde los potenciales impactos ambientales y los reclamos están orientados a: la generación de polvo, vibraciones, ruido. Las mayorías de inconformidades se presenta en vía a la costa en la ciudad de Guayaquil, donde las urbanizaciones están en conflicto con las canteras, lo cual se debe a la limitada planificación para el ordenamiento territorial.

La evolución que han tenido los conflictos sociales en el sector minero del Ecuador, estuvieron en su inicio concentrados a la erradicación del trabajo infantil, posteriormente a la regularización de la minería artesanal, la asociatividad de los mineros artesanales para transformarse en pequeña minería, control de la delincuencia y actualmente se concentra en la erradicación de la minería ilegal.

La aceptabilidad de los proyectos mineros en la comunidad depende de varios factores: conservación de áreas protegidas, conservación del agua y usos de suelo, antropología del comportamiento, inversión local mediante las regalías del sector minero, empleabilidad de personal local, responsabilidad corporativa y cadenas de suministros inclusiva.

Los grandes proyectos mineros presentan una mayor cantidad de casos de conflictos sociales en relación con la minería artesanal y pequeña minería. Manifestándose inconformidades por parte de actores como: comunidades locales, grupos de indígenas, grupos de grupos de conservación y mineros artesanales, éstas en su mayoría han sido motivadas por el temor a la afectación de las fuentes de agua, al despojo de sus tierras, y pérdidas de zonas protegidas.

La gran minería y la pequeña minería actualmente trabajan en desarrollar la resolución de sus conflictos mediante la coexistencia de la minería artesanal con las empresas dentro de sus concesiones, bajo las restricciones y lineamientos que define el concesionario mediante mutuo acuerdo. Promoviendo la convivencia entre la minería a diferentes escalas, como un medio para la distribución equitativa de los recursos y el desarrollo socioeconómico local y nacional.

Así como existió una larga época del auge del petróleo en el Ecuador, se prevé un importante crecimiento del sector minero por la presencia de los grandes proyectos mineros, que han permitido realizar una importante inversión en la exploración de los recursos minerales en el país, lo cual hace diez años era una gran debilidad porque no se conocían las probables reservas, actualmente estamos en la etapa final de la exploración avanzada en la gran minería, lo que permitirá dar una continuidad hacia una explotación que se viene esperando hace siete años.

Sin duda la falta de inversión, carencia de conocimiento geológico y prospección de los recursos minerales impedía al país este desarrollo que sí se ha visto en los países cercanos como Chile, Perú, Bolivia, Colombia, que son una muestra del potencial geológico minero en América Latina y que demuestra que la minería es un sector clave para el desarrollo económico como ha ocurrido en Chile y Perú, donde existe una alta producción y diversidad en el aprovechamiento de los metales, sin concentrar su producción solo en el oro como ocurría antes en él Ecuador.

\section{Discusión}

La metodología utilizada para el levantamiento y validación de la información, permitió identificar la percepción y postura que tienen los distintos sectores (Gobierno Central, Gobiernos Locales, Comunidad, Universidades, Fundaciones y Grupos de Conservación, Empresas Mineras) en el país sobre el desarrollo y la política minera, mediante análisis bibliográfico, entrevistas, encuestas en zonas mineras de metálicos y no metálicos. Donde se observa que los principales proyectos estratégicos y de segunda generación están actualmente finalizando su exploración avanzada, lo cual permitirá la fase de explotación en el 2020 , cabe mencionar que la aceptación social de los proyectos ha sido variable en los diferentes sectores del país, lo cual se considera que está en función del involucramiento de la comunidad local en los proyectos de inversión social ejecutados con las regalías, conocimiento social y cultural del sector y la estrategia comunicacional.

Con los descubrimientos de yacimientos metálicos de alta ley se ha constatado que el potencial minero que posee el Ecuador es importante y puede ser rentable la explotación en el país, con un crecimiento esperado del sector minero del $4 \%$ en el PIB para el 2021, lo cual permitirá un crecimiento de la producción y se diversificará el aprovechamiento de otros metales, para no concentrar la producción solo en el oro, como se ha venido realizando en los últimos años. Esto se puede verificar con los proyectos con los que cuenta el país: cinco proyectos estratégicos y 6 de segunda generación. Entre los que destaca el proyecto Cascabel de la empresa SolGold PLC, del depósito mineral Alpala, que según los datos del 2019 se convertiría en la mina subterránea más grande de plata, tercera de oro y sexta de cobre en el ranking mundial.

El Estado ha pretendido volver a la actividad más atractiva para la inversión extranjera como para la nacional, lo que se evidencia con la publicación de la nueva política minera del estado que van de la mano con las reformas propuestas actualmente a la Ley de Minería vigente desde el año 2009. Sin embargo, este proceso de desarrollo minero ha tenido una lenta evolución debido a factores económicos durante la negociación de contratos, a retrasos en tiempo para que los grandes proyectos alcancen una exploración avanzada que les permitan pasar a la explotación, y a los conflictos sociales por presencia de minería ilegal.

Los recursos no metálicos incluyen el aprovechamiento de 13 minerales, donde los 3 minerales de mayor representatividad son: caliza, arcillas, piedra pómez, las concesiones de no metálicos están con- 
centradas principalmente en la región sierra y oriental, en las provincias de Carchi, Sucumbíos, Pichincha, Morona Santiago, Azuay, El Oro, Loja y Zamora Chinchipe. La explotación de recursos no metálicos presenta un mayor nivel de aceptación social, porque es un sector con el que culturalmente se ha convivido en el país y esto ha permitido tener un mayor conocimiento sobre este sector.

Los materiales de construcción constituyen los minerales que presentan un mayor volumen de explotación en el Ecuador, debido al desarrollo de la construcción. Se encuentran distribuidas en todo el país, teniendo un menor número en las provincias orientales de Orellana, Pastaza y Morona Santiago.

En el Ecuador en general se realiza cuatro prácticas comunes orientadas al desarrollo económico y bienestar comunitario: 1) obligaciones económicas por ley, que corresponde a la inversión en el Estado a través de pago de regalías, impuestos, utilidades, 2) contratación de personal local y nacional 3) Desarrollo de proyectos de emprendimiento orientados al sector agropecuario, y de alimentos 4) actividades locales que incluyen; capacitación, fiestas locales, inversión en escuelas, vías, etc.

Uno de los principales problemas sociales es la delincuencia y la minería ilegal que genera un alto riesgo a la seguridad para los trabajadores de las operaciones mineras y para las poblaciones cercanas, debido a enfrentamientos armados y lavados de activos que se han registrado en los últimos años.

América Latina es una región de importantes reservas minerales, con altos niveles de exportación de estos recursos, por lo cual la gobernanza de los recursos naturales, especialmente en la minería en América Latina constituye un tema prioritario para garantizar una cooperación multilateral para el desarrollo económico del Estado, mercado, encadenamientos productivos, manejo de conflictos sociales, desafíos en el aprovechamiento sostenible de recursos minerales y para promover métodos de gestión para la conservación del agua, suelo y bosques.

\section{Referencias}

Aillón Vásconez, M.I. 2016. Energía y Recursos Naturales: Historia de las normas mineras en Ecuador. 24/6/19, https://www.pbplaw.com

Agencia de Regulación y Control Minero. 2012. Reglamento de contabilidad para minería metálica a gran escala para los contratos de explotación minera. Registro Oficial No. 663.

Agencia de Regulación y Control Minero. 2019a. Informe de rendición de cuentas ARCOM 2018. Informe oficial, Quito, 11 págs.

Agencia de Regulación y Control Minero. 2019b. EI sector minero generó USD 41,8 millones en el primer cuatrimestre del 2019. 24/6/19, http://www. controlminero.gob.ec

Asamblea Nacional. 2008. Constitución de la Repúbli- ca del Ecuador. Registro Oficial 449 de 20-oct-2008. Asamblea Nacional. 2009. Ley de minería [en línea]. 2009. Ecuador. Registro Oficial Suplemento 517.

Asamblea Nacional. 2011. Ley Orgánica de la Economía Popular y Solidaria. Ecuador. Registro Oficial 444.

Asamblea Nacional. 2014. Reglamento de Seguridad y Salud en el trabajo en el Ambito Minero. Resolución Registro Oficial 247 de 16-may.-2014

Asamblea Nacional. 2015. Ley Orgánica de Incentivos para Asociaciones Público Privadas. Registro Oficial Suplemento 652.

Avci, D., Fernández-Salvador, C. 2016. Territorial dynamics and local resistance: Two mining conflicts in Ecuador compared. The Extractive Industries and Society, 3 (4), 912-921.

Banco Central Del Ecuador. 2019. La economía ecuatoriana creció $1,4 \%$ en 2018. 24/6/19, https://www. bce.fin.ec

Bárcena, A. 2018. Estado de situación de la minería en América Latina y el Caribe: desafíos y oportunidades para un desarrollo más sostenible. IX Conferencia de Ministerios de Minería de las Américas, Lima, 47 págs.

Carrión, A. 2017. Las leyes de minería en Ecuador a fines del siglo XIX: la reconfiguración de la propiedad minera. Procesos: revista ecuatoriana de historia, 45, 95-122-

Dirección Nacional de Síntesis Macroeconómica. 2019. Reporte de Minería. Banco Central del Ecuador, Quito, 25 págs.

Drobe, J. 2007. Update on Inferred Resource Estimate 43-101 Technical Report. Panantza Copper Project, Corriente Resources Inc., Reporte técnico. Vancouver. 46 páginas.

Empresa Nacional Minera. 2019a. Portafolio de proyectos 2019. 24/6/19, https://www.enamiep.gob.ec

Empresa Nacional Minera. 2019b. Informe de rendición de cuentas año 2018. Informe oficial, Quito, 31 págs.

Espí, J.A. 2001. El libro de la minería del oro en lberoamérica. Red XIII-B, CYTED, 398 pp.

Frakaland Vangsnes, G. 2018. The meanings of mining: A perspective on the regulation of artisanal and small-scale gold mining in southern Ecuador. The Extractive Industries and Society, 5 (2), 317-326.

García, E. 2016. El impacto social de la minería a gran escala en el Ecuador. Tesis de maestría, Universidad Andina Simón Bolívar, Quito, 161 págs.

Gasparini, R. 2017. El sector minero ecuatoriano y la influencia de los flujos de inversión chinos y canadienses en su estructura regulatoria (20002013). Tesis de maestría, Facultad Latinoamericana de Ciencias Sociales, Flacso Ecuador, Departamento de Estudios Internacionales y Comunicación, Guayaquil, 140 págs.

Gutierrez, A. 2002. Dioses, símbolos y alimentación en los Andes: interrelación hombre-fauna en el Ecuador prehispánico. Abya Yala, Quito, 473 pp. 
Illescas, R. 2018. Perspectivas del sector minero en el Ecuador. 24/6/19, http://servicios.industrias.gob.ec/

IPEC SUDAMERICA. 2002. Línea de Base Trabajo infantil en la minería artesanal del oro en Ecuador. Organización internacional del trabajo, Oficina regional para América Latina y el Caribe, Centro Desarrollo y Autogestión (DyA). Lima. 145 págs.

António Mateus and Luís Martins. 2019. Challenges and opportunities for a successful mining industry in the future. Boletín Geológico y Minero, 130 (1), 99-121.

Ministerio de Economía y Finanzas. 2019. USD 3.800 millones de inversión minera hasta 2021 darán Más Prosperidad al Ecuador. 24/6/19, https://www. finanzas.gob.ec

Ministerio de Recursos Naturales No Renovables. 2009. Reglamento general a la Ley de Minería. S.I.: Decreto Ejecutivo 119. Registro Oficial Suplemento 67 de 16-nov.2009.

Ministerio de Energía y Recursos Naturales No Renovables. 2019. Informe de rendición de cuentas 2018. Informe oficial, Quito, 106 págs.

Ministerio de Ambiente. 2016. Reglamento Ambiental de Actividades Mineras. Acuerdo Ministerial 37, Registro Oficial Suplemento 213 de 27-mar.-2014.

Ministerio de Minería. 2016. Plan Nacional de Desarrollo del Sector Minero. Quito, 305 págs.

Morejón, G. 2012. Ambiente Ecuador: Breve historia de la minería en el Ecuador y sus implicaciones ambientales. 24/6/19, http://biobanco.blogspot. com/

Presidencia de la República. 2009. Reglamento General de la Ley de Minería. Zaruma, Suplemento Registro Oficial No. 67.

Price, J.G. 2019. Opportunities in global mineral resources. Boletín Geológico y Minero, 130 (1), 47-56.

Vela-Almeida, D., Kolinjivadi, V. And Kosoy, N. 2018. The building of mining discourses and the politics of scale in Ecuador. World Development, 103, 188198.

Sandoval, F. 2001. La pequeña minería en el Ecuador. Reporte No. 75, International Institute for Environment and Development, World Business Council for Sustainable Development, Mining, Minerals and Sustainable Development, Quito, 31 págs.

Sandoval, F., Albán, J., Carvaja, M., Chamorro, C., Pazmiño, D. 2001. Capítulo 7- Minería, Minerales y Desarrollo Sustentable en Ecuador. Informe, Mining, Minerals and Sustainable Development (MMSD),

World Energy Trade. 2019. El Gobierno de Ecuador presentó este martes el programa para explotación minera, proyectado a 2030. 24/6/19, https:// www.worldenergytrade.com

Yánez Paz, J. 2018. El rol de la asociatividad como medio de inclusión laboral de género: caso asociación de mujeres Jancheras "Las Águilas" del sector minero Camilo Ponce Enríquez, en la provincia del Azuay. Trabajo de fin de grado, Pontificia Universidad Católica del Ecuador, Quito, 113 págs. +25 págs. (anexos).

Recibido: julio 2020

Revisado: diciembre 2020

Aceptado: enero 2021

Publicado: diciembre 2021 
